\title{
28 Resarch Square \\ Prevalence of Eating Disorders Among Nutritional Sciences Students and Dietitians in Saudi Arabia
}

Renad Ahmad Tarawah ( $\square$ renad.t@outlook.sa )

Umm Al- Qura University

El-Sayed Bakr

Umm Al- Qura University

Research Article

Keywords: eating disorder, EAT-26, DSM-5, dietitians, nutrition students.

Posted Date: December 29th, 2021

DOl: https://doi.org/10.21203/rs.3.rs-1191223/v1

License: (1) This work is licensed under a Creative Commons Attribution 4.0 International License. Read Full License 


\section{Abstract}

Background: Eating disorders (EDs) involve persistent disturbed eating and related behaviors that result in altered consumption or absorption of food with potential physical or psychological function impairment. EDs have four major types: anorexia nervosa, bulimia nervosa, binge eating disorder, and eating disorder not otherwise specified. The investigation aimed to study the prevalence of EDs by assessing nutritional status for nutrition students and dietitians from multiple provinces in Saudi Arabia.

Methods: A cross-sectional study comprising 175 male and female nutrition students or dietitians. EDs were diagnosed using EAT-26 and DSM5. Dietary intake was estimated by repeated 24-hr recall records. Diet was analyzed using food processor nutrition and fitness software. Intakes were compared with the recommended dietary allowances.

Results: According to EAT-26 diagnostic criteria, the prevalence of EDs was $15.4 \%$. The mean age was $24.96 \pm 4$ years. ED subjects had normal BMls. The diet analysis showed that these subjects had a lower intake of energy, macronutrients, and some micronutrients, and other micronutrients were high as compared to the RDA.

Conclusion: EDs were more prevalent among dietitians than students. The EDs comprised a high number of OSFED and UNFED cases. Subjects with an ED had an unbalanced diet with poor nutrition.

\section{Plain English Summary:}

The article presents the prevalence of male and female nutrition students and dietitians with eating disorders from different provinces in Saudi Arabia. Eating disorders are defined by two diagnostic criteria. Prevalence of eating disorders was $15.4 \%$ among nutrition students and dietitians. Some types of eating disorders were more prevalent than other types. eating disorders were more prevalent in some Saudi provinces. Also, the article shows the energy, macronutrient, and micronutrients intake that was low for some micronutrients, and other micronutrients were high compared to the recommended dietary allowances. This is the first study in Saudi Arabia that investigate the prevalence of eating disorder among nutrition students and dietitians.

\subsection{Introduction}

\subsection{Background}

Eating disorders (ED) are illnesses that are defined as persistent disturbed eating and eating-related behaviors that result in altered consumption or absorption of food and potential physical or psychological function disruption. EDs have four major types as described by The Diagnostic and Statistical Manual of Mental Disorders (DSM-5): anorexia nervosa (AN), bulimia nervosa (BN), binge eating disorder (BED), and eating disorder not otherwise specified (EDNOS) [1].

AN is defined as a psychological illness or syndrome. It is characterized by an intense fear of fatness or seeking low body weight. The body mass index (BMI) is reported to be very low at less than $17.5 \mathrm{~kg} \backslash \mathrm{m} 2$. Affected individuals restrict their high-fat food intake and participate in excessive exercise ${ }_{[2]}$. 
BN is the second type of ED and is a life-threatening psychiatric illness, characterized by overeating by eating high caloric food in a short time with self-induced vomiting, laxative and diuretic use, fasting, or over-exercising to avoid weight gain [3].

BED is considered the third ED type and is characterized by eating a large amount of food in a short time compared to normal individuals. Sufferers also feel guilty or depressed after eating, consume food alone to avoid embarrassment, and eat food even when not hungry. To diagnose BED, the binge episodes must occur once/week for 3 months or more, and the syndrome must not be influenced by any normal compensating behavior [4].

EDNOS is defined in DSM-5 as those who have an ED but have not satisfied the diagnostic criteria for any of the previous ED types. The most recent DSM-5 update renamed this type as other specified feeding or eating disorder (OSFED), which includes several illnesses such as purging disorder, atypical AN, subthreshold BN, and subthreshold BED [5].

Unspecified feeding or eating disorder (UFED) is applied to those who have an ED but have not achieved the diagnostic criteria for any of the previous types or for OSFED.

\subsection{Nutritional status of eating disorders}

Nutrition plays a major role among ED individuals. Malnutrition is common because of the low consumption of macro- and micronutrients in AN and BN. Moreover, the restricting behavior can affect micronutrient availability, resulting in compromised immunity, loss of lean body mass, fatigue, altered brain function, and deficiencies in vitamin D, calcium, folate, cobalamin, zinc, magnesium, thiamine, riboflavin, niacin, pyridoxine, $C, E, K$, and iron, leading to anemia. Replacing these nutrients is an important part of nutrition therapy to enhance recovery $[6,7]$.

\subsection{Health consequences of eating disorders}

EDs can affect multiple organ systems and are potentially life threatening. These disorders can lead to changes in the gastrointestinal system. Food restriction and vomiting can cause digestion and normal stomach functions to be interrupted, thus leading to nausea, blotting, gastroparesis, constipation, anemia, and blood sugar fluctuations. EDs can also affect the cardiovascular system [8].

AN has specific health consequences due to caloric distraction. Symptoms include hypokalemia, hypoglycemia, abdominal discomfort, and loss of bone mineral density [9]. BN is associated with subsequent xerosis, an electrolyte imbalance leading to arrhythmias, early satiety, gastroparesis, constipation related to laxative abuse, gastroesophageal reflux, and malnutrition [10]. BED also has its own particular complications, such as diabetes, dysphagia, diarrhea, blotting, nutrient deficiencies, and increased risk of cancer, hypertension, and obstructive sleep apnea [11].

\subsection{Epidemiology_of eating_disorders}

The epidemiological incidence of EDs in the United Kingdom was reported to be AN 7.4\%; BN 0.8\%, BED 3.6\%, and OSFED 2.4\%. In Finland, the prevalence of AN among females was 3.6\%, and OSFED 0.6\%. In Holland, ED among females was 3.7\%, AN 1.2\%, BN 0.6\%, BED 1.6\%, and OSFED 0.3\%, and among males EDs were $0.5 \%$, 
AN and BN each $0.1 \%$, and BED 0.3. In Switzerland, among females, AN was $1.9 \%$, and among males $0.2 \%$. In Germany, AN was found to be $0.3 \%$, BN $0.4 \%$, and BED $0.5 \%$. In Sweden, for females, BN was $1.6 \%$ and BED $0.4 \%$. In Australia, ED was reported to be $16.3 \%$, AN 0.46\%, BN 0.66\%, and BED 5.58\%. In the United States, AN among females was found to be $1.37 \%$ and BED 1.7\%, and BED among males was $0.8 \%$. In Canada, female EDs were reported to be at a level of $4.46 \%$, AN 0.06\%, BN 2.01\%, and BED 0.68\%; among males, ED was $2.21 \%$, BN 1.31\%, and BED 0.16\% [12].

The prevalence of EDs in the Middle East and North Africa (MENA) region was found to be 16.9\% in the UAE (for BED, specifically). Egypt had a 65.0\% prevalence of EDs. In Saudi Arabia (Dammam), 29.4\% of females had an ED, whereas this figure was $35 \%$ and $23.3 \%$ for Taif and Arar cities, respectively $[13,14,15,16]$

\subsection{Literature Review}

\subsection{Literature review}

Another study aimed to determine the frequency of AN and EDs among dietitians. The study was performed with a 2500 sample size. Participants were asked to complete two types of questionnaires-the Orthorexia Nervosa Questionnaire (ORTO-15) and the Eating Disorder Examination Questionnaire (EDE-Q)-and their anthropometrics were measured. The authors reported that $49.5 \%$ of participants were at high risk for AN and $12.9 \%$ at high risk for ED. $8.2 \%$ of the participants reported that they had been previously treated for an ED, and $44.6 \%$ had been treated for AN. The limitation of this study was that the response rate was only $26 \%$, the sample size was low relative to the total, and those at high risk could be recovering from any illness that made them at risk for an ED [17].

In another study, the objective was to assess ED behavior and addiction to food among nutrition and nonnutrition students. There were 967 participants included. The study was performed by sending questionnaires by e-mail to the students, enquiring about demographic data such as age, sex, race, height, and weight. For ED screening, the Eating Attitude Test (EAT-26) was used; as a self-assessment tool to measure three dimensions of eating behaviors, the Three-Factor Eating Questionnaire (TFEQ-R18) was employed, and the Yale Food Addiction Scale (YFAS) was used as a tool to model to DSM-5. 10\% of the participants were found to be of high concern regarding an ED, and $10.3 \%$ had a food addiction. According to the observed EAT-26 scores, $8.8 \%$ of respondents were underweight or normal, and $12.9 \%$ were overweight or obese. The limitations of this study were that it was biased because of the self-report approach; the authors did not assess for general psychopathology, they only included undergraduate students, and they excluded graduate students [18].

The previous two studies were conducted in the United States. In a study performed in Brazil, the authors aimed to determine the number of risk behaviors of EDs and body image satisfaction among nutrition students and dietitians; 743 female participants were analyzed. Data were collated using an online questionnaire-the Body Shape Questionnaire (BSQ) - to evaluate individuals' satisfaction with their own body; EAT-26 was also used. $10.1 \%$ of undergraduate students reported having an ED, whereas among dietitians, this figure was $7.9 \% .5 \%$ of dietitians were underweight, $72.3 \%$ normal, $16.4 \%$ overweight, and $6.3 \%$ obese. For undergraduate students, $11 \%$ were underweight, $73.3 \%$ normal, $10.5 \%$ overweight, and 5.2 obese. The limitations of this study are that 
the participants were all female, the authors only used EAT-26 to diagnose EDs, and the research was biased due to the use of the self-report online questionnaire ${ }_{[19]}$.

Accordingly, our investigation aimed to study the prevalence of EDs by assessing nutritional status for nutrition students and dietitians from multiple provinces in Saudi Arabia.

\subsection{Research hypothesis}

Eating disorder tendencies are prevalent in both the nutrition students and dietitians. However, nutrition students will score higher on the EAT-26, that because they are gaining new knowledge about diets and food that could affect them in terms of losing or gaining weight potentially indicating higher level of ED tendencies.

\subsection{Methodology}

\subsection{Study type and duration}

An epidemiological, descriptive, cross-sectional study was conducted in Saudi Arabia between October 2020 and March 2021.

\subsection{Study setting and sampling}

Nutrition students and dietitians from different nutrition colleges and hospitals aged 18 to 55 years were the target group. Subjects with chronic diseases such as diabetes, hypertension, hypo/hyperthyroidism, as well as pregnant and lactating woman were excluded from the study. Only subjects in a dietetic school at any academic level and dietitians were eligible for inclusion.

\subsection{Data collection}

Participants were screened using a form translated into the Arabic language of the Eating Attitude Test (EAT26). EAT-26 is a widely used tool for screening EDs following a 6-point Likert scale (always, usually, often, sometimes, rarely, never). The original version of the EAT-26 was published in 1982. A score of above 20 is indicative of a possible ED. Table (1) shows the scoring system for EAT-26. Scores between 20-24 indicate mild ED, 25-30 moderate to severe ED, and more than 31 very severe ED [20].

\section{Table (1): Scoring system for EAT-26.}

\begin{tabular}{|lll|}
\hline & Questions 1-25 & Question 26 \\
\hline Always & 3 points & 0 points \\
\hline Usually & 2 points & 0 points \\
\hline Often & 1 point & 0 points \\
\hline Sometimes & 0 points & 1 point \\
\hline Rarely & 0 points & 2 points \\
\hline Never & 0 points & 3 points \\
\hline
\end{tabular}


The questionnaire was distributed to the participants in the form of an electronic online questionnaire using Google forms distributed via social media consisting of three parts: 1) consent form, 2) personal informationname, age, gender, province, college, academic level, weight, and height, and 3) the translated EAT-26. All participants whose scores indicated possible EDs were included, and they underwent further diagnosis by DSM5 .

\subsubsection{Diagnostic criteria}

DSM-5 was used to identify the types of ED (pica, rumination disorder, avoidance \restriction disorder, AN, BN, BED, OSFED and UFED) by telephone-calling the participants with ED, asking whether they had symptoms recorded in the DSM-5 to identify its type ${ }_{[21]}$.

\subsubsection{Anthropometric Measurements}

Weight and height were asked in the electronic questionnaire as a self-reported measurement. BMI was

calculated using the Quetelet equation:

$$
\mathrm{BMI}=\frac{\text { weight }(\mathrm{kg})}{\text { height }\left(\mathrm{m}^{2}\right)} \text {. }
$$

\subsubsection{Dietary assessment}

Dietary intake was estimated using twice-repeated 24-hour recall records focusing on energy. In addition, the following nutrients and macronutrients were recorded: [carbohydrates (gm), protein(gm), fat(gm)] and micronutrients: [vitamin $A(\mu g)$, thiamin $(\mathrm{mg})$, riboflavin $(\mathrm{mg})$, niacin $(\mathrm{mg})$, pantothenic acid(mg), pyridoxine(mg), biotin $(\mu \mathrm{g})$ folate $(\mu \mathrm{g})$, cobalamin $(\mu \mathrm{g})$, vitamin $\mathrm{C}(\mathrm{mg})$, vitamin $\mathrm{D}(\mu \mathrm{g})$, vitamin $\mathrm{E}(\mathrm{mg})$, vitamin $\mathrm{K}(\mu \mathrm{g})$, calcium(mg), chromium( $\mu \mathrm{g})$, copper(mg), fluoride $(\mathrm{mg})$, iodine $(\mu \mathrm{g})$, iron( $(\mathrm{mg})$, magnesium(mg), manganese(mg), phosphorus(mg) potassium(mg), sodium(mg), selenium( $\mu \mathrm{g})$, and zinc(mg)].

\subsection{Ethical considerations}

Ethical permission to conduct the current study was obtained from the local committee for bio-medical ethics to conduct scientific research at Umm Al-Qura University. Participants had provided their consent prior to the beginning of the project, and they were assured that all their information would be treated with privacy and that they had the right to withdraw from the study at any time without any problem.

\subsection{Pretesting of questionnaires}

The data collection tools were pretested on 5 subjects not included in the study to confirm the clarity of the questions and any necessary changes before the main project was conducted.

\subsection{Data analysis}

Microsoft Excel was used to initially enter and analyze the data. The recall records were analyzed using food processor nutrition and fitness software by ESHA research version 11.9.13. Intake values were compared with the recommended dietary allowance (RDA) for energy, macronutrients, and micronutrients and were obtained from the National Institutes of Health $(\mathrm{NIH})_{[22]}$. Descriptive and inferential data were analyzed using statistical 
for social science software (IBM SPSS statistics version 26). A P-value of $\leq 0.05$ was set as the significance level.

\subsection{Results}

\subsection{Background information}

A total of 186 participants (14 males and 172 females) were recruited from different provinces in Saudi Arabia. Two participants were excluded because they were not nutrition students or dietitians, and for 9 participants, contact was lost. The final total number of participants included in the study was, therefore, 175; thus, the completion rate was $94 \%$. The mean age of participants was $24.62 \pm 4.7$ years, the minimum age was 19 years, and the maximum age was 53 years. Participants who had been previously treated for an ED accounted for $3.4 \%(n=6)$, and $96.6 \%$ had never been treated for an ED $(n=169)$.

\subsection{EAT-26 and DSM-5}

According to EAT-26, participants scoring $\geq 20$ are classified with an ED. According to the results, 27 participants (15.4\%)-2 males and 25 females-had an ED, as shown in Figure (1). 26.9\% ( $n=8)$ of the cases had a mild ED, $26.9 \%(n=8)$ a moderate to severe ED, and $40.7 \%(n=11)$ had a very severe ED. The mean age for cases with EDs was $24.96 \pm 4$ years.

One participant (3.7\%) had AN, 1 (3.7\%) BN, 2 (7.4\%) BED, 7 (25.9\%) OSFED, and 16 (59.3\%) had UFED, as shown in Figure (2).

Regarding those with an ED, according to their place of residency, 6 cases (22.2\%) were from Eastern Province, 1 case (3.7\%) from Hail province, 1 case (3.7\%) from Jizan province, 5 cases (18.5\%) from Mecca province, 11 cases (40.7\%) from Medina province, and 3 cases (11.1) were from Riyadh province, as shown in Figure (3).

Regarding participants' academic level, 5 subjects (18.5\%) were in the fifth academic level, 1 (3.7\%) in seventh, 2 (7.4\%) in eighth, 1 (3.7\%) was an intern, and $18(66.7 \%)$ had graduated.

\subsection{Anthropometric measurements}

Subjects' anthropometric measurements with ED mean values are listed in Table (2). The mean height was 159 $\pm 6.8 \mathrm{~cm}$, mean weight $59.6 \pm 8.7 \mathrm{~kg}$, and the mean BMI was $23.6 \pm 3.47$ for participants with an ED. Hence, there were significant differences regarding weight and $\mathrm{BMI}-$ the $p$. value was 0.036 and 0.016 , respectivelywithin those with ED as compared to participants without ED.

Moreover, the reference data of BMI categories indicated a higher prevalence of normal weight among ED cases rather than underweight, overweight, and obesity, as noted in Table (3).

\section{Table (2): Anthropometric measurements of subjects with an eating disorder.}




\begin{tabular}{|lll|}
\hline Anthropometrics & Mean \pm SD & $p$. value \\
\hline Height $(\mathrm{cm})$ & $159 \pm 6.8$ & 0.843 \\
Weight $(\mathrm{kg})$ & $59.6 \pm 8.7$ & 0.036 \\
\hline BMI $\left(\mathrm{kg} / \mathrm{m}^{2}\right)$ & $23.6 \pm 3.47$ & 0.016 \\
\hline
\end{tabular}

Table (3): BMI categories for subjects with eating disorders.

\begin{tabular}{lll} 
BMI Category & & \\
\hline Category & No. & Percentage (\%) \\
\hline Underweight & 1 & 3.7 \\
Normal weight & 19 & 70.4 \\
Overweight & 5 & 18.5 \\
Obesity I & 2 & 7.4
\end{tabular}

\subsection{Dietary assessment}

Participants with an ED declared either high or low intakes of macronutrients and/or micronutrients based on their twice-repeated 24-h dietary recall records. The consumption was less than the RDA for energy, carbohydrate, protein, fat, vitamins including $A, D, E, C, B_{1}, B_{2}, B_{3}, B_{5}, B_{7}, B_{9}$, and $B_{12}$ as well as minerals including calcium, chromium, copper, fluoride, iodine, potassium, magnesium, phosphorus, and zinc; moreover, there was a slight reduction from the RDA for vitamin $\mathrm{B}_{6}, \mathrm{~K}$, and selenium. However, the consumption of iron, manganese, and sodium was higher than the RDA, as illustrated in Table (4 \& 5).

Table (4): Macronutrient and vitamin intake of participants with eating disorders. 


\begin{tabular}{|llll|}
\hline Nutrient & Mean \pm SD & RDA & \% Of RDA \\
\hline Energy $(\mathrm{kcal})$ & $1358.2 \pm 661.6$ & 2044 & 66.4 \\
\hline Carbohydrate $(\mathrm{gm})$ & $169.2 \pm 85.6$ & 280.48 & 60.67 \\
\hline Protein $(\mathrm{gm})$ & $59.25 \pm 21.4$ & 76.7 & 77.5 \\
\hline Fat $(\mathrm{gm})$ & $55.62 \pm 36.5$ & 68.48 & 80.5 \\
\hline Vitamin $\mathrm{A}(\mu \mathrm{g})$ & $245.24 \pm 182.5$ & 714.81 & 34.2 \\
\hline Vitamin $\mathrm{B}_{1}(\mathrm{mg})$ & $0.68 \pm 0.39$ & 1.1 & 62.12 \\
\hline Vitamin $\mathrm{B}_{2}(\mathrm{mg})$ & $0.86 \pm 0.44$ & 1.1 & 78 \\
\hline Vitamin $\mathrm{B}_{3}(\mathrm{mg})$ & $12.54 \pm 6.15$ & 14.15 & 88.8 \\
\hline Vitamin $\mathrm{B}_{5}(\mathrm{mg})$ & $1.19 \pm 0.93$ & 5 & 23.9 \\
\hline Vitamin $\mathrm{B}_{6}(\mathrm{mg})$ & $1.17 \pm 0.87$ & 1.3 & 90.14 \\
\hline Vitamin $\mathrm{B}_{7}(\mu \mathrm{g})$ & $2.9 \pm 2.57$ & 30 & 9.67 \\
\hline Vitamin $\mathrm{B}_{9}(\mu \mathrm{g})$ & $178.5 \pm 111.8$ & 400 & 44.63 \\
\hline Vitamin $\mathrm{B}_{12}(\mu \mathrm{g})$ & $1.72 \pm 1.31$ & 2.4 & 71.68 \\
\hline Vitamin $\mathrm{C}(\mathrm{mg})$ & $57.5 \pm 72.3$ & 76.1 & 75.5 \\
\hline Vitamin $\mathrm{D}(\mu \mathrm{g})$ & $1.8 \pm 2.3$ & 15 & 12 \\
\hline Vitamin $\mathrm{E}(\mathrm{mg})$ & $3.8 \pm 3.1$ & 15 & 25.33 \\
\hline
\end{tabular}

Results from 24-hr recall records. Mean \pm SD, RDA, and \% of RDA.

Table (5): Mineral intake of participants with eating disorders. 


\begin{tabular}{|llll|}
\hline Nutrient & Mean \pm SD & RDA & \% Of RDA \\
\hline Calcium $(\mathrm{mg})$ & $683.9 \pm 475$ & 1000 & 68.4 \\
\hline Chromium $(\mu \mathrm{g})$ & $0.78 \pm 0.82$ & 25.74 & 3 \\
\hline Copper $(\mathrm{mg})$ & $0.53 \pm 0.28$ & 900 & 59 \\
\hline Fluoride $(\mathrm{mg})$ & $0.04 \pm 0.08$ & 3.07 & 1.36 \\
\hline Iodine $(\mu \mathrm{g})$ & $1.8 \pm 1.6$ & 150 & 0.8 \\
\hline Iron $(\mathrm{mg})$ & $38 \pm 154$ & 17.26 & 216 \\
\hline Magnesium $(\mathrm{mg})$ & $137.37 \pm 74.3$ & 317.78 & 43.56 \\
\hline Manganese $(\mathrm{mg})$ & $4.42 \pm 17.4$ & 1.8 & 244.9 \\
\hline Phosphorus $(\mathrm{mg})$ & $617.4 \pm 323.4$ & 700 & 88.2 \\
\hline Potassium $(\mathrm{mg})$ & $1543 \pm 620.6$ & 2659.26 & 58.2 \\
\hline Sodium $(\mathrm{mg})$ & $2421.3 \pm 995.6$ & 1500 & 161.4 \\
\hline Selenium $(\mu \mathrm{g})$ & $52 \pm 21.8$ & 55 & 94.5 \\
\hline Zinc $(\mathrm{mg})$ & $4.6 \pm 2.2$ & 8.22 & 56.5 \\
\hline
\end{tabular}

Results from 24-hr recall records. Mean \pm SD, RDA, and \% of RDA.

\subsection{Correlation between EAT-26 and nutrient intake}

The obtained data showed significant correlations for ED parameters according Eat-26 scores. There was a significant correlation between EAT-26 and energy consumption $(P$. value $=0.005)$, carbohydrate $(P$. value= $0.009)$, vitamin $\mathrm{B}_{2}(P$. value $=0.025)$, vitamin $\mathrm{B}_{12}(P$. value $=0.001)$, vitamin $\mathrm{D}(P$. value $=0.003)$, calcium $(P$. value $=0.032)$, iron $(P$. value $=0.000)$, magnesium $(P$. value $=0.005)$, phosphorus $(P$. value $=0.001)$, and zinc $(P$. value $=0.001$ ), as listed in Table (6). Meanwhile, there was an insignificant correlation between EAT-26 and protein consumption $(P$. value $=0.268)$, fat $(P$. value $=0.052)$, vitamin $\mathrm{B}_{9}(P$. value $=0.396)$, and vitamin $\mathrm{C}(P$. value=0.368), as outlined in Table (6).

Table (6): Significant and insignificant correlations between EAT-26 and nutrient intake. 


\begin{tabular}{|c|c|c|c|}
\hline Parameter & $\begin{array}{l}\text { Nutrient } \\
\text { intake }\end{array}$ & $\begin{array}{l}P . \\
\text { value }\end{array}$ & $\begin{array}{l}\text { Pearson } \\
\text { correlation }\end{array}$ \\
\hline \multirow[b]{6}{*}{$\begin{array}{l}\text { Eating } \\
\text { disorder }\end{array}$} & Energy & 0.005 & .527 \\
\hline & Carbohydrate & 0.009 & .494 \\
\hline & Protein & 0.268 & 0.221 \\
\hline & Fat & 0.052 & 0.379 \\
\hline & Vitamin $B_{2}$ & 0.025 & .431 \\
\hline & Vitamin $\mathrm{B}_{9}$ & 0.396 & 0.170 \\
\hline \multirow[t]{8}{*}{ EAT-26 score } & Vitamin $B_{12}$ & 0.001 & .584 \\
\hline & Vitamin C & 0.368 & 0.181 \\
\hline & Vitamin D & 0.003 & .557 \\
\hline & Calcium & 0.032 & .414 \\
\hline & Iron & 0.000 & .737 \\
\hline & Magnesium & 0.005 & .527 \\
\hline & Phosphorus & 0.001 & .596 \\
\hline & Zinc & 0.003 & .544 \\
\hline
\end{tabular}

Data illustrated as p-value and Pearson correlation.

\subsection{Discussion}

Our investigation aimed to study the prevalence of EDs by assessing the nutritional status of nutrition students and dietitians from multiple provinces in Saudi Arabia.

\section{$\underline{5.1 \text { Prevalence of eating disorders }}$}

Our results showed that the percent was $6.9 \%$ and $93.1 \%$ of males and females, respectively, suffered from an ED. These results agreed with [18], who found that $15.6 \%$ and $84.4 \%$ of males and females, respectively, had an ED, from a total of 147 nutrition students. In the present study, EDs were more prevalent between 19 and 30 years and less prevalent in 31-50-year-olds, with only 3 participants affected by an ED, whereas the age group $>50$ years old recorded no ED incidence. The mean age was 24.96 years, agreeing with [19], who recorded a mean age for students of 22.5 years and, for dietitians, 31.2 years. Meanwhile, those who have been treated previously from ED in the current study count for $3.4 \%$, and $8.2 \%$ of 636 participants were found to be treated from an ED in [17].

In our study, the prevalence of ED (15.4\%) was high for OSFED and UNFED compared to other EDs. A similar study conducted in Brazil that included 745 female participants showed an ED prevalence of $9.10 \%$; the study included only females due to Brazilian female dietitians comprising more than $90 \%$ of the total [19]. [18] included 147 participants only as students in the United States and found an ED prevalence of 
9.5\%. Meanwhile, [23] analyzed 97 participants in Australia and reported an ED prevalence of 14.5\% for nutrition students. [24] also carried out research in Australia that included 137 nutrition students and dietitians and found this prevalence to be $13.25 \%$. [15] investigated 35 participants in Wisconsin, United States, reporting this value for nutrition students and dietitians to be $22.2 \%$. Furthermore, the ED rate variance between studies reflected the difference of ED prevalence among nutrition students and dietitians with respect to geographic regions worldwide; the variation might have been due to differences in socioeconomic status, and knowledge about EDs could affect and lead to an ED. Notably, all studies have used EAT-26 to measure EDs.

According to our data, EDs were more prevalent (40.7\%) in Medina province despite the percent of participants from Medina and Mecca provinces being equal. Moreover, ED was high (22.2\%) in the Eastern province as compared to the number of participants included. Some provinces did not declare an ED because the participants were few in number when compared to the total population in other provinces. Two of the provinces (Al- Jowf and Najran) were not included in the study because no participants completed the questionnaire in these provinces, and only one participant was included from Asser province. In other provinces, the study did not detect ED, and the number of participants who completed the questionnaire was slightly low. Further research is required to include more participants from those provinces with low sample numbers.

For the current study, students $(n=9)$ compared to dietitians $(n=18)$ had less incidence of EDs. A study in Brazil disagreed with these findings; students with an ED comprised 43 participants and dietitians 25 participants [19]. In the present study, for those with an ED, 5 participants were in their third academic year, 4 in their fourth, and no participants were reported in their first/second academic year. In another study, 4 participants were in their first/second academic year, and 10 participants were in their third/fourth academic year [18]. However, with a small sample size, it is difficult to make a definitive conclusion.

Our data demonstrated an AN level of 3.7\%, BN 3.7\%, BED 7.4\%, OSFED 25.9\%, and UNFED 59.3\% from a total of 27 cases. Another study from Jordan found that $31.8 \%$ of 421 subjects reported suffering from an AN [26]. A Greek study investigating 215 undergraduate students found this AN incidence to be 68.2\% [27]. In the United States, $44.6 \%$ of 636 subjects had AN [17], indicating that most of them included only AN of the ED types. In Australia, a 23\% BN prevalence was found [23], and in Brazil, using 179 nutrition students, the BN rate was reported as $6.1 \%$, with BED being $2.8 \%$ [28]. Unfortunately, no study included OSFED and UNFED among nutrition students and dietitians.

\subsection{Anthropometric measurements}

Our research demonstrated that participants with ED had a normal BMI (average $23.6 \mathrm{~kg} / \mathrm{m}^{2}$ ). Only one case was underweight, 19 were normal, five were overweight, and two were obese (Table 3). A study in the United States revealed that, on average, the BMI was within underweight/normal classification eleven cases, and two cases were overweight/ obese [18]. According to a study conducted in Australia, the average BMI was normal $\left(22.7 \mathrm{~kg} / \mathrm{m}^{2}\right)[24]$.

In the current study average height $159 \mathrm{~cm}$, and weight $59.6 \mathrm{~kg}$; there was a significant difference for weight and BMI within those with ED and an insignificant difference for height.

\section{$\underline{5.3 \text { Dietary assessment }}$}

Page $12 / 18$ 
EDs patients were more susceptible to nutrient deficiencies. The present study revealed that most participants had an inadequate diet, and the average intake of energy, macronutrients (carbohydrate, protein, and fat), energy, and macronutrients were below the RDA (energy intake $1358.2 \mathrm{kcal}$, carbohydrate $169.2 \mathrm{~g}$, protein 59.25 $\mathrm{g}$, and fat $55.62 \mathrm{~g}$ ). [27] found intake for AN respondent for energy to be $25.5 \mathrm{kcal} / \mathrm{kg}$, carbohydrate $195.3 \mathrm{~g}$, protein $66.8 \mathrm{~g}$, and fat $69.7 \mathrm{~g}$; these values are below the RDA for energy, carbohydrate, and protein and within the RDA for fat.

They also included one micro nutrient the sodium and the intake were $2260.4 \mathrm{mg}$ (i.e., higher than the RDA). In our study, sodium intake was $2421.3 \mathrm{mg}$ (i.e., higher than the RDA). Unfortunately, no study has investigated other nutrients, and research has yet to be performed to include all types of ED and macro-micronutrient intake among nutrition students and dietitians. There were significant differences between EAT-26 and intake of energy and carbohydrates, whereas there was an insignificant difference between EAT-26 and protein and fat intake.

\subsection{Strength and limits}

This study has some limitations because it used a self-report online questionnaire and had a low number of participants. However, due to limited time and resources, it was not possible to include larger numbers of nutrition students and dietitians. Biomarkers would have given strong inferences to the results of the current study. Further studies are necessary to conduct biochemical analyses.

Strength points our study is the first in Saudi Arabia to investigate the prevalence of EDs among nutrition students and dietitians.

\subsection{Conclusion And Recommendation}

\subsection{Conclusion}

Our investigation may conclude that the prevalence of eating disorders in Saudi Arabia to be 15.4\% among nutrition students and dietitians. The EDs comprised a high number of OSFED and UNFED cases. Moreover, eating disorders were more prevalent in some Saudi provinces. Energy, macronutrient, and some micronutrients were low, and other micronutrients were high compared to the recommended dietary allowances (RDA).

\subsection{Recommendations}

According to the findings of this study, the following recommendations are suggested:

1. Further research with a larger sample size must be performed to support the study's findings and investigate other types of ED that this study did not include.

2. Assessment of people with EDs should be comprehensive and include physical, psychological, and social needs. Analysis of various biochemicals must be carried out in future research because they are surrogate measures for dietary intake.

3. Education and counseling should be provided for those with an ED regarding the impact of these disorders on their health, nutritional behavior, and nutrition misinformation. This approach could involve conducting nutrition campaigns, providing education to participants. 
4. Pamphlets with information about the seriousness of EDs and health consequences should be distributed to limit the prevalence of EDs among this group.

\section{Declarations}

\section{What is already known on this subject}

The prevalence of EDs among nutrition students and dietitians in different countries worldwide, and the dietary intake of those with EDs. The study needs to be done to investigate the number of dietitians and nutrition students with EDs in Saudi Arabia.

\section{What your study adds}

The percentage of dietitian and nutrition students with EDs in Saudi Arabia from different provinces and their dietary intake.

\section{Funding}

The authors declare that no funds, grants, or other support were received during the preparation of this manuscript.

\section{Competing Interests}

The authors have no relevant financial or non-financial interests to disclose.

\section{Author Contributions}

All authors contributed to the study conception and design. Material preparation, data collection and analysis were performed by Renad Tarawah and El-Sayed Bakr. The first draft of the manuscript was written by Renad Tarawah and all authors commented on previous versions of the manuscript. All authors read and approved the final manuscript.

\section{Data Availability.}

The datasets generated during and analyzed during the current study are available from the corresponding author on reasonable request.

\section{Ethics approval}

This study was performed in line with the principles of the Declaration of Helsinki. Approval was granted by the local committee for bio-medical ethics to conduct scientific research at Umm Al-Qura University (12/04/2021/ MUVR120421).

\section{Consent to participate}

Informed consent was obtained from all individual participants included in the study.

\section{Acknowledgment}


Many thanks to all the participants who were included in this research; without their kind help and honesty, this work could not be done.

\section{References}

1. Hirschhorn, L., 2019. Perceptions of Disordered Eating Among Dietetic Students - Proquest. [online] Search.proquest.com. Available at:

https://search.proquest.com/openview/79b2bbf5552da64423c777d1db5c80cf/1.pdf?pqorigsite $=$ gscholar $\& \mathrm{cbl}=18750 \&$ diss $=\mathrm{y}$.

2. Legg, T., 2018. Anorexia Nervosa: Symptoms, Causes, And Treatment. [online] Medicalnewstoday.com. Available at: https://www.medicalnewstoday.com/articles/267432 .

3. Brazier, Y., 2017. Bulimia Nervosa: Symptoms, Treatment, And Risks. [online] Medicalnewstoday.com. Available at: https://www.medicalnewstoday.com/articles/105102.

4. McCuen-Wurst, C., Ruggieri, M. and Allison, K., 2018. Disordered eating and obesity: associations between binge-eating disorder, night-eating syndrome, and weight-related comorbidities. Annals of the New York Academy of Sciences, [online] 1411(1), pp.96-105. Available at: https://nyaspubs.onlinelibrary.wiley.com/doi/abs/10.1111/nyas.13467.

5. Riesco, N., Agüera, Z., Granero, R., Jiménez-Murcia, S., Menchón, J. and Fernández-Aranda, F., 2018. Other Specified Feeding or eating disorders (OSFED): Clinical heterogeneity and cognitive-behavioral therapy outcome. European Psychiatry, [online] 54, pp.109-116. Available at: http://www.europsy- journal.com.

6. Barnard, Neal D., editor. 2018. "Eating Disorders." Nutrition Guide for Clinicians, 3rd ed., Physicians Committee for Responsible Medicine, nutritionguide.pcrm.org/nutritionguide/view/Nutrition_Guide_for_Clinicians/1342074/all/Eating_Disorders.

7. Scribner, C., 2016. Understanding Nutritional Needs of Patients with Eating Disorders: Implications for Psychiatrists. [online] Psychiatric Times. Available at:

https://www.psychiatrictimes.com/view/understanding-nutritional-needs-patients-eating-disordersimplications-psychiatrists.

8. Kaye, W., 2018. Health Consequences. [online] National Eating Disorders Association. Available at: https://www.nationaleatingdisorders.org/health-consequences.

9. Chidiac, C., 2019. An update on the medical consequences of anorexia nervosa. Current Opinion in Pediatrics, 31(4), pp.448-453.

10. Gibson, D., Workman, C. and Mehler, P., 2019. Medical Complications of Anorexia Nervosa and Bulimia Nervosa. Psychiatric Clinics of North America, [online] 42(2), pp.263-274. Available at: https://pubmed.ncbi.nlm.nih.gov/31046928/.

11. Wassenaar, E., Friedman, J. and Mehler, P., 2019. Medical Complications of Binge Eating Disorder. Psychiatric Clinics of North America, [online] 42(2), pp.275-286. Available at: https://linkinghub.elsevier.com/retrieve/pii/S0193953X19300152.

12. Lindvall Dahlgren, C., Wisting, L. and Rø, $\varnothing$., 2017. Feeding and eating disorders in the DSM-5 era: a systematic review of prevalence rates in non-clinical male and female samples. Journal of Eating Disorders, [online] 5(1), pp.5-7. Available at: https://jeatdisord.biomedcentral.com/articles/10.1186/s40337-017-0186-7. 
13. Melisse, B., de Beurs, E. and van Furth, E., 2020. Eating disorders in the Arab world: a literature review. Journal of Eating Disorders, [online] 8(1), pp.1-19. Available at:

https://jeatdisord.biomedcentral.com/articles/10.1186/s40337-020-00336-X.

14. Fatima, W., Fatima, R. and Anwar, N., 2018. Prevalence of Eating Disorders among Female College Students of Northern Broader University, Arar, Kingdom of Saudi Arabia. International Journal of Child Health and Nutrition, [online] 7(3), pp.115-121. Available at: https://www.researchgate.net/publication/339617424_Kingdom_of_Saudi_Arabia.

15. El-Azeem Taha, A., Abu-Zaid, H. and El-Sayed Desouky, D., 2018. Eating Disorders Among Female Students of Taif University, Saudi Arabia. Archives of Iranian medicine, [online] 21(3), pp.111-117. Available at: https://pubmed.ncbi.nlm.nih.gov/29688736/.

16. Alwosaifer, A., Alawadh, S., Abdel Wahab, M., Boubshait, L. and Almutairi, B., 2018. Eating disorders and associated risk factors among Imam Abdulrahman bin Faisal university preparatory year female students in Kingdom of Saudi Arabia. Saudi Medical Journal, [online] 39(9), pp.910-921. Available at: https://www.ncbi.nlm.nih.gov/pmc/articles/PMC6201000/.

17. Tremelling, K., Sandon, L., Vega, G. and McAdams, C., 2017. Orthorexia Nervosa and Eating Disorder Symptoms in Registered Dietitian Nutritionists in the United States. Journal of the Academy of Nutrition and Dietetics, [online] 117(10), pp.1612-1617. Available at: https://www.ncbi.nlm.nih.gov/pmc/articles/PMC5623148/.

18. Yu, Z. and Tan, M., 2016. Disordered Eating Behaviors and Food Addiction among Nutrition Major College Students. Nutrients, [online] 8(11), p.673. Available at: https://pubmed.ncbi.nlm.nih.gov/27792162/.

19. Toral, N., Gubert, M., Spaniol, A. and Monteiro, R., 2016. Eating disorders and body image satisfaction among Brazilian undergraduate nutrition students and dietitians. Archivos latinoamericanos de nutricion, [online] 66(2), pp.129-134. Available at: https://pubmed.ncbi.nlm.nih.gov/29737669/.

20. Garner, D., Olmsted, M., Bohr, Y. and Garfinkel, P., 1982. The Eating Attitudes Test: psychometric features and clinical correlates. Psychological Medicine, 12(4), pp.871-878.

21. Benson, S., Young, S., Akaka, J., Bernstein, C., Crowley, B., Everett, A., et al 2013. Diagnostic and statistical manual of mental disorders. 5th ed. Arlington: American Psychiatric Publishing, pp.329-354.

22. Stallings, V., Harrison, M. and Oria, M., 2019. Dietary Reference Intakes for Sodium and Potassium. Washington, DC: National Academies Press, pp.565-577.

23. Rocks, T., Pelly, F., Slater, G. and Martin, L., 2017. Prevalence of Exercise Addiction Symptomology and Disordered Eating in Australian Students Studying Nutrition and Dietetics. Journal of the Academy of Nutrition and Dietetics, 117(10), pp.1628-1636.

24. Rocks, T., Pelly, F., Slater, G. and Martin, L., 2017. Eating attitudes and behaviours of students enrolled in undergraduate nutrition and dietetics degrees. Nutrition \& Dietetics, 74(4), pp.381-387.

25. Woehrer, K., 2018. Prevalence of Eating Disorders Tendencies, Disordered Eating, and Orthorexia Nervosa Behaviors in Dietetic-Nutrition Students Compared to Biology Students. University of Wisconsin-Stout, pp.1-42.

26. Abdullah, M., Al Hourani, H. and Alkhatib, B., 2020. Prevalence of orthorexia nervosa among nutrition students and nutritionists: Pilot study. Clinical Nutrition ESPEN, [online] 40, pp.144-148. Available at: https://clinicalnutritionespen.com/article/S2405-4577(20)30362-4/fulltext. 
27. Grammatikopoulou, M., Gkiouras, K., Markaki, A., Theodoridis, X., Tsakiri, V., Mavridis, et al., 2018. Food addiction, orthorexia, and food-related stress among dietetics students. Eating and Weight Disorders Studies on Anorexia, Bulimia and Obesity, [online] 23(4), pp.459-467. Available at: https://link.springer.com/article/10.1007/s40519-018-0514-1.

28. de Moraes, C., Appolinário, J., Mourilhe, C., de Freitas, S. and da Veiga, G., 2021. Reliability of the Brazilian version of the questionnaire on eating and weight patterns-5 (QEWP-5). Eating and Weight Disorders Studies on Anorexia, Bulimia and Obesity, [online] 26(3), pp.1-8. Available at: https://link.springer.com/article/10.1007\%2Fs40519-020-01072-6.

\section{Figures}

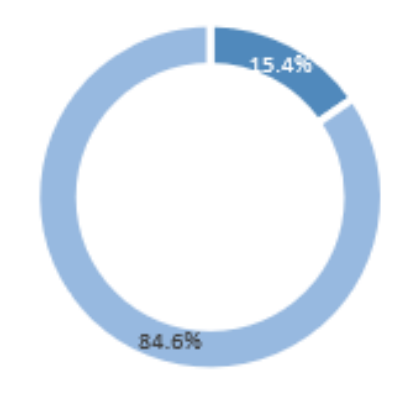

- with ED without ED

\section{Figure 1}

Participants with/without eating disorders

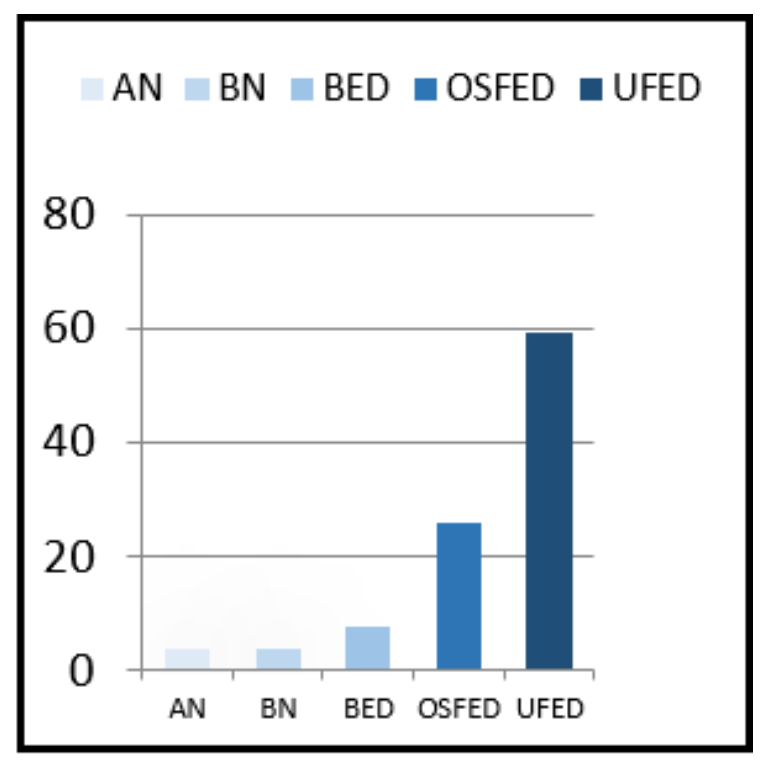


Figure 2

Participants with ED according to DSM-5 categories

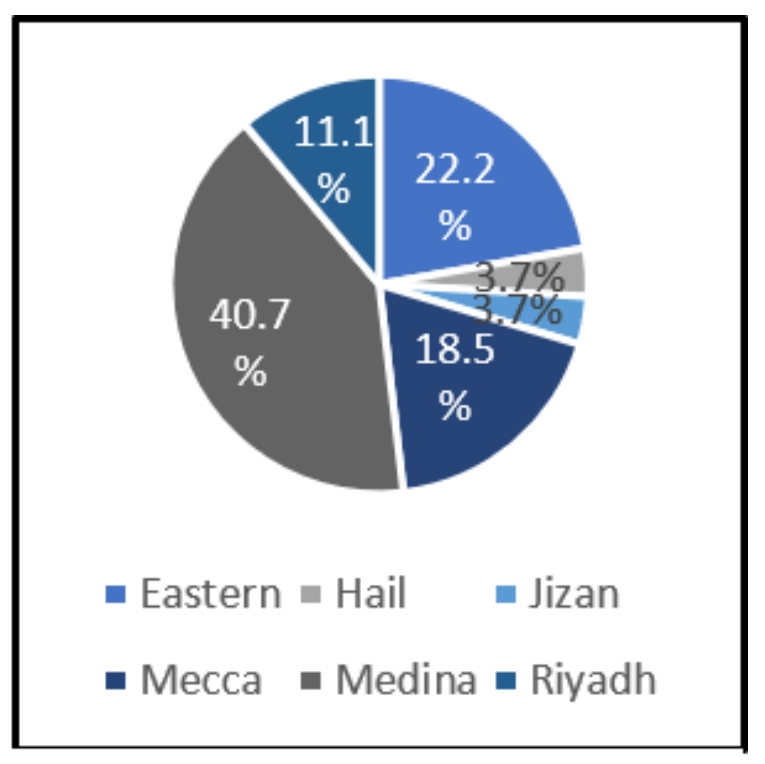

Figure 3

Participants with ED according to their provinces

\section{Supplementary Files}

This is a list of supplementary files associated with this preprint. Click to download.

- Table3.tif

- Table2.tif

- Table1.tif

- Table6.tif

- Table5.tif

- Table4.tif

- eat26ratingscale.pdf 